\title{
Review of Jack Russell Weinstein's Adam Smith's pluralism: rationality, education, and the moral sentiments. New Haven \& London: Yale University Press, 2013, 360 pp.
}

\author{
CRAIG SMITH \\ University of Glasgow
}

Jack Russell Weinstein's new book sets itself two major tasks: to argue that Adam Smith offers "a coherent philosophy of education that permeates his system" (p. 216) and that Smith's thinking is interestingly attuned to the very modern problem of pluralism. The first strand of argument seeks to provide a way of reading Smith that demystifies some of the remaining ambiguity across his oeuvre. The second sees in Smith an anticipation of current debates about cultural diversity and pluralism.

In seeking to apply Smithian ideas in a contemporary setting Weinstein rejects the limiting over-emphasis on contextualism. His approach accepts the importance of getting Smith 'right' through historically informed readings, but denies that this is where the inquiry must cease. As Weinstein himself admits this is a difficult task (p. 9), but it is a potentially profitable approach and one which is proving increasingly attractive. Weinstein aims to examine Smith's potential contribution to contemporary debates on pluralism by offering "the first full-length investigation of Smith's philosophy of education and his theory of rationality" (p. 15).

Weinstein provides an interpretation of Smith that sees his writings as characterised by the desire to provide an expansive account of human rationality. He points out Smith's attempts to distance himself from a dependence on formal logic and stresses Smith's interest in rhetoric and narrative notions of learning and rationality. The early chapters trace Smith's interaction with Mandeville, Shaftesbury, and Hutcheson, suggesting that his dissatisfaction with elements of the thought of each is combined with a facility for absorbing what is of use. There is a particularly interesting comparison of Smithian spectatorship and Shaftesbury's soliloquy (p. 44), which opens the way into the idea of rationality that runs through Weinstein's reading. Both Smith's impartial spectator and Shaftesbury's soliloquy involve 
"dialogical self-division" that results in the need for "rational adjudication" between competing mental features in a given context (p. 44).

The book has three significant contemporary interlocutors: Alasdair MacIntyre, Michel Foucault, and James Otteson. The account of rationality provided is clearly influenced by MacIntyre; in the closing chapters Foucault is considered in terms of the notion of progress in history and the extent to which he may have failed to grasp Smith's views; Otteson on the other hand appears as a foil in the initial part of the book. A great deal of time is spent establishing that Weinstein is offering an alternative to Otteson's (2002) use of the metaphor of the 'Marketplace' in his account of Smith's theory. The objection seems more than a little manufactured. As Weinstein admits, the two agree on a large range of issues; the disagreement as he sees it is that by using the metaphor of the marketplace Otteson might mislead readers into prioritising market-like interactions in reading The theory of moral sentiments [TMS] (p. 50) or into viewing the market as Smith's sole organisational principle (p. 65). But the disagreement seems to be less about their very similar accounts of unintended consequences and more about potential misreading and extensions of the market into other areas (via homo economicus). This strikes me as a manufactured disagreement in that the underlying similarities of the two authors are ignored in favour of a rhetorical disagreement. Otteson's account of Smith does not depend on homo economicus, nor does it invite any but the most superficial reader to see that as Smith's view. He uses the market as a metaphor for more general spontaneous order accounts-including Smith's argument in TMS-while accepting that the general model has important nuances in its application. Weinstein appears to accept this point (p. 66). But he then goes on to say that the metaphor is misleading because Smith's moral theory does not include 'exchange'. This is a very strange claim from someone who will later dwell at length on how humans react to the judgments of others and learn from the exchange of emotional cues before making an explicit comparison between Smith's views on price and the impartial spectator (pp. 152-153).

More troubling still is Weinstein's argument that for Smith the rules of morality are not spontaneous but rather are progressive and the product of rational inquiry (p. 66). This bodes ill for what follows as it suggests confusion about one of Smith's central points: that there 
is a distinction between the abstract reasoning of a philosopher, who explains morality and accounts for it, and the everyday individual who experiences and reflects upon moral issues. The idea that morality is subject to deliberate refinement through philosophical interaction is at odds with the entire spirit of Smith's mode of inquiry where the philosopher seeks to reveal the already existent chains that link ordinary moral thinking. The source of this strange reading becomes clear when Weinstein introduces his central organisational concept.

Weinstein's exploration of Smith's views on rationality focuses on what he sees as the sophisticated rumination on the nature of rationality in TMS. The aim is to explain how Smith moves away from calculative notions of reasoning to develop an understanding of the human mind that links sentimental motivation with rational reflection through the idea of the impartial spectator. The impartial spectator demonstrates "Smith's commitment to the rational adjudication of multiple motivations of an act" (p. 57). It is "an anthropomorphization of the rational process and incorporates the sentimental foundations into the reasoned analysis" (p. 76).

Weinstein provides an interesting account of Smith as moral psychologist, along the way demonstrating that there is no crude bifurcation of the accounts of rationality between TMS and The wealth of nations, but the crux of his reading lies in the view that Smith's account of the operation of sympathy and spectatorship as a form of reflection is helpfully understood as part of more general account of reasoning. Here Weinstein's account proves slightly less convincing. It rests on showing that Smith thought that calculative reasoning and deductive logic were distinct from more sentimental, rhetorical and narrative forms of understanding, and then bringing these back together in an expanded account of rationality. Leaving aside the question of whether the discussion of motivation from sentiment as a prompt to reasoning is as fully fleshed out as it might be in the light of Smith's place in the development of sentimentalist moral psychology, I am still left with the sense that Weinstein is overegging the 'reasoned' nature of the reflection involved in the operation of the impartial spectator. In explaining the detail of the operation of spectatorship Weinstein accurately describes the sophisticated moral thought process attributed to it by Smith. Judgment is certainly brought to bear, information is certainly assessed in an imaginative manner and decisions are reached-but the process as Smith described it is emotional and 
imaginative rather than calculative. One wonders then what is to be gained by reading the imaginative and emotional reflection of Smithian agents as part of a theory of 'rationality' rather than a more general anatomy of moral psychology that combines rational, sub-rational, and emotional elements. It is not clear what interpretative gains are made by using 'reason' derived from the impartial spectator as grounds for bringing them together.

Moreover, Smith describes a process that is oftentimes near instantaneous, often sub-conscious, and is recognised as a feeling more akin to the direct drive of a passion rather than a deliberative calculation. Weinstein is right to say that Smith did not think that all of our mental processes were akin to rational calculation, and that he had a deep interest in narrative, context, and rhetoric, but Smith was also describing in great detail a process that more often than not occurs instantaneously. Most of what we do, most of the time, is not the result of conscious reflection: it is the result of sub-conscious assessment or the following of socialised or habitual rules. To incorporate these into 'rationality' seems less than helpful if we are seeking to understand or anatomise the various elements of moral psychology. In other words Smith might have had good analytical reasons not to include these elements of moral experience under the heading of rationality.

The main thrust of Weinstein's view here is that there is a "rationality implicit in the moral sentiments" (p. 109), which in turn leads to the view that: "Sympathy is a rational process; it is not a form of intuition" (p. 111). So the heart of the rationality reading of Smith's moral psychology lies in the fact that "A person's self-awareness derives from the socially constructed rational self-reflection informed by the judgments of others" (p. 70), or "the conscious use of rationality to adjudicate between competing positions" (p. 109) concerning the moral sentiments. But applying a reading of the moral sentiments and sympathy as deliberative elides a whole range of other possibilities. Part of the problem here is the division between the intuitive and the deliberative that frames the discussion.

Weinstein admits that socialisation and learning from social norms and the judgments of others is a key part of Smith's account, but the intuitive/deliberative division leads him to ignore the central role of a third vital category in Smith's account of moral psychology: sub-rational learning, habit formation, and emotional-indeed aesthetic-decisionmaking (p. 112). Weinstein, for all of his attention to socialisation, views 
this apart from the account of deliberation, and only offers a much attenuated discussion of habit at the end of the section in question (p. 127).

When Weinstein returns to the theme of the sub-conscious he rightly notes that intuition and deliberation are not either/or for Smith-but one might also want to argue that nor are they exhaustive of mental experience. Weinstein accepts that "what appears as intuition may very well be the product of long-standing deliberation, education, and acculturation" (p. 158), but he then insists that the fact that the impartial spectator is invoked in adjudicating between competing sources of motivation and information means that this aspect of Smith's account, where 'reasoned' reflection takes place, is the central element of moral experience. As Weinstein himself notes (p. 162), Smith accepted that most 'reasoned' justification is post-hoc-so moral agents do not in most cases engage in the sort of moral reflection about their actions that Weinstein sees as part of rationality, until afterwards when we try to understand our actions. The impartial spectator does indeed 'speak' to us, but it is only on reflection that we come to see what he has based his advice upon.

In a similar vein Weinstein makes a clear connection between Smith's account of language and his 'reasoned' approach to moral psychology (pp. 176-177), but in so doing he pays insufficient attention to the fact that according to Smith we acquire language in a non-deliberative fashion and our day to day use of it in communication is habitual and 'un-thinking' rather than deliberative and analytical. People express themselves through the learned habits of their language; they do not reflect on these as they speak. Weinstein is right that Smith is interested in illustration and rhetoric and less concerned with formal logic, and he does make interesting points about the relationship between the sentiments and reason and about Smith's use of system. But his focus on bending all of Smith's account of moral experience into an overarching account of rationality leaves him stressing an overly deliberative interpretation of the impartial spectator's place in the totality of moral experience. The impartial spectator is but one part of Smith's account. It is a very interesting and innovative part, but privileging it to the extent that we see here provides us with a somewhat skewed reading of TMS.

Bringing this approach to the theme of pluralism leads Weinstein to make two interesting claims about the impartial spectator. The first is 
that: "Smith's goal is for the moral agent to become as impartial as possible while still understanding that it is not immoral to prefer oneself to others [...]" (p. 141). It is certainly true that Smith describes the operation of a psychological process whereby we develop an impartiality check that ensures our actions match the standards of propriety, but the impartial spectator-as the quotation above notes-is more than willing to approve of self-regarding behaviour that passes the test of what an impartial spectator would regard as appropriate. Smith is providing us with a descriptive account of conscience. Whether it makes sense to then say that Smith advocates increased impartiality or increased attention to the voice of an already impartial feature of our psychology is left open in the discussion that follows, as Weinstein moves on to the idea of educating our impartial spectators.

The second interesting claim is that Smith's approach leaves him uniquely placed to provide an account that addresses the modern preoccupation with the problems of social pluralism arising from ethnically and culturally diverse populations co-existing within the same political system. Weinstein rightly observes that Smith accepts difference as a "fact" (p. 25), and that important aspects of his systematic thinking, such as stadialism, represent attempts to understand diversity (p. 29). The discussion of Foucault in the penultimate chapter trades on the differences between Smith and Foucault on the extent of universals in human nature and human knowledge, or, to be more accurate, on the extent of our possible knowledge of universals. But Weinstein's account here seems over optimistic in its view of Smith's attitude to diversity. Certainly Smith accepted diversity, but far from seeing it as valuable for moral education to the extent that it aids sympathy by extending experience (p. 83), it seems rather to be something that he sought to 'deal' with as best as he was able.

Overplaying Smith's acceptance of diversity into a celebration of it fails to account for the role of socialisation within a group which is a key stage in Smith's account of moral 'education' (the very point raised in Weinstein's chapter about socialisation as education for social unity). Smith clearly struggled with the fact of the diversity of moral practices, perhaps most famously in the infanticide discussion at the end of Part 5 , chapter II, of TMS, but the account offered here of a more rationalistic Smith committed to the growth of knowledge through the extension of moral judgment among diverse people seems to read too much of a twenty-first century sensibility back onto Smith. Compared to the 
account of similar aspects of Smith offered by Fonna Forman-Barzilai (2010) the account here seems overly enthusiastic in reading as a strength what Smith more probably saw as a problem for his approach.

It is true, as Weinstein argues, that Smith saw competition between religious sects as useful in preventing domination. But it seems too much to say that this shows Smith's desire to institutionalise and support diversity (p. 23), rather than him noticing a useful unintended consequence of the fact of a diversity of religious beliefs. These sects are still dangerous in Smith's view and they may still hate each other, but they have come to a modus vivendi. There is no moralised "fusion of horizons" or recognition by sect members of the value of other sects. It is only as the philosopher with an overview that we can see the unintended benefits of religious competition. Smith seems to believe in a universal ethic, but provides a theory that sees moral belief as generated in context. There is no easy way of squaring that conflict by a progressive and rationalistic reading of the impartial spectator.

In the second part of the book Weinstein moves on to consider improvements in rational judgment. Here the first couple of chapters focus on education. Again the same strategy is at play. Weinstein wants to use an over-arching notion of education to capture all of what Smith has to say about socialisation, formal teaching, and the improvement of humans' decision-making capacity. Once again the detail here is clearly depicted and for the most part convincing. The worry lies with the more general aim of conflating all forms of human 'learning' under one heading. Weinstein acknowledges the distinctions between socialisation, informal knowledge and education while seeking to bring them together under a broad organisational principle. Formal education and socialisation are forms of knowledge acquisition vital for Smith, but they are not the same, and so it is not clear that it makes sense to place them under the same heading. Moreover, as with 'rationality' it is not clear that 'education' proves a useful analytic to get at the heart of what Smith thought about such matters.

One is left with a series of interesting discussions of aspects of Smith's view of psychology and learning, but the over-capacious conceptions of reason and education, while revealing in some respects, obscure important aspects of Smith's analysis-most obviously his deep interest in sub-rational, emotional, and habitual processes. Moreover, one gets the sense that Weinstein's initial desire to show that Smith could be of use in dealing with contemporary issues of pluralism 
seems to be driving the use of the over-arching conceptions of rationality and education, leading to a reading which seems in places strained as it seeks to make Smith relevant in a social and political debate whose terms he could not have foreseen.

\section{REFERENCES}

Forman-Barzilai, Fonna. 2010. Adam Smith and the circles of sympathy. Cambridge: Cambridge University Press.

Otteson, James R. 2002. Adam Smith's marketplace of life. Cambridge: Cambridge University Press.

Craig Smith is the Adam Smith lecturer in the Scottish Enlightenment in the School of Social and Political Sciences at the University of Glasgow. He is the author of Adam Smith's political philosophy: the invisible hand and spontaneous order (Routledge, 2006), and is book-review editor of the Adam Smith Review.

Contact e-mail: <Craig.Smith@glasgow.ac.uk> 